\title{
EWSR1 gene rearrangement occurs in a subset of cutaneous myoepithelial tumors: a study of 18 cases
}

\author{
Uta Flucke $^{1}$, Gabriele Palmedo ${ }^{2}$, Nina Blankenhorn ${ }^{2}$, Pieter J Slootweg ${ }^{1}$, Heinz Kutzner ${ }^{2}$ \\ and Thomas Mentzel ${ }^{2}$ \\ ${ }^{1}$ Department of Pathology, Radboud University Nijmegen Medical Centre, Nijmegen, The Netherlands and \\ ${ }^{2}$ Dermatopathologie Bodensee, Friedrichshafen, Germany
}

\begin{abstract}
Cutaneous myoepithelial tumors form a clinicopathological spectrum ranging from mixed tumor to myoepithelioma and myoepithelial carcinoma. Recently, EWSR1 rearrangement has been described in a subset of soft tissue myoepithelial tumors, whereas the cutaneous counterparts showed this aberration in a minority of cases. This raises the question whether cutaneous myoepithelial tumors have comparable genetic alterations. We examined 18 cases of cutaneous myoepithelial tumors arising in 7 female and 11 male patients (age range, 34-86 years; mean, 58 years). Eight mixed tumors occurred at the head, and one at the scrotum. Six myoepitheliomas arose at the extremities, and one case each at the back and head. One myoepithelial carcinoma occurred at the cheek. The tumor size ranged from 0.3 to $1.7 \mathrm{~cm}$ (mean, $1.0 \mathrm{~cm}$ ). All mixed tumors and three myoepitheliomas were limited to the dermis. Four myoepitheliomas and the myoepithelial carcinoma involved the subcutis. Mixed tumors and myoepitheliomas were composed of myoepithelial cells with a variable cytomorphology, architecture and stromal background. Ductal structures were seen by definition in mixed tumors. The myoepithelial carcinoma represented an infiltrative dermal neoplasm consisting of atypical spindle cells. Immunohistochemically, all cases tested were positive for EMA and calponin, whereas S100, CK, ASMA and GFAP were expressed in $90 \%, 80 \%, 78 \%$ and $50 \%$ of the cases tested, respectively. By fluorescent in situ hybridization analysis, 7 out of 16 cases (44\%) exhibited EWSR1 rearrangement. Four of them were mixed tumors, two were myoepitheliomas and one was a myoepithelial carcinoma, confirming that these lesions represent a spectrum of dermal myoepithelial tumors. Follow-up information, available for five patients (including the patient with a myoepithelial carcinoma), revealed no evidence of disease in all cases (range, 6-72 months). Our study provides a genetic relationship of myoepithelial tumors of the skin with their counterparts in soft tissue, bone and visceral localization by sharing EWSR1 rearrangement.

Modern Pathology (2011) 24, 1444-1450; doi:10.1038/modpathol.2011.108; published online 1 July 2011
\end{abstract}

Keywords: EWSRI rearrangement; FUS rearrangement; mixed tumors; myoepithelial tumors; skin

Cutaneous myoepithelial tumors form a continuous clinicopathological spectrum ranging from benign mixed tumor to myoepithelioma and myoepithelial carcinoma. Although mixed tumors are not uncommon, purely myoepithelial tumors are very rare and only few and small series have been reported. ${ }^{1-4}$

The presence of preexisting myoepithelial cells in the skin and viscera (eg, salivary glands, breast and

Correspondence: Dr U Flucke, MD, Department of Pathology, Radboud University Nijmegen Medical Centre, PO Box 9101, Nijmegen $6500 \mathrm{HB}$, The Netherlands.

E-mail: u.flucke@pathol.umcn.nl

Received 24 March 2011; revised 11 May 2011; accepted 12 May 2011; published online 1 July 2011 lung) renders probably a pathogenetic difference with myoepithelial tumors of the soft tissue in which a normal counterpart does not exist.

As a consequence of the variability of myoepithelial cells, different morphological patterns and a heterogeneous immunophenotype with alternating positivity for epithelial (keratins, EMA), myogenic (ASMA and calponin) and neurogenic markers (S100 and GFAP) occur. $^{1-6}$ Although criteria for malignancy in myoepithelial tumors of soft tissue have been established by moderate to severe nuclear atypia, the minimal criteria for malignancy among myoepithelial neoplasms of the skin remain uncertain., ${ }^{4,6,7}$

Hornick and Fletcher ${ }^{4}$ reported that increased mitotic activity (up to 6 mitoses/10 HPF) among 
cytologically benign cutaneous myoepitheliomas might predict recurrence and metastases. Furthermore, it has been suggested that in the absence of malignant cytomorphology and confirmed metastatic disease, infiltrative margins, satellite tumor nodules, tumor necrosis and involvement of deep structures are ominous signs. ${ }^{8}$ Fully malignant myoepitheliomas with malignant cytomorphology are known for their potential of aggressive behavior such as their soft tissue counterparts. ${ }^{6,9}$

A recently published study showed that a subset of myoepithelial tumors, especially in the soft tissues, harbor EWSR1 rearrangement with different fusion partners, and these genetic changes were reported in only two of six of cutaneous myoepithelial neoplasms. ${ }^{10}$ Therefore, it seemed appropriate to look for genetic similarities in a larger cohort of cutaneous myoepithelial tumors.

\section{Materials and methods}

The cases were retrieved from the (referral) files of two of the authors (TM, HK), and clinical details and follow-up were obtained from the referring physicians. In all the cases, the tissue was fixed in $4 \%$ buffered formalin, routinely processed and embedded in paraffin; $2-4 \mu \mathrm{m}$ thick sections were stained with hematoxylin and eosin and immuno-

Table 1 Details of used immunohistochemical antibodies

\begin{tabular}{llcl}
\hline Antibody & Clone & Dilution & Source \\
\hline ASMA & 1A4 & $1: 500$ & DAKO \\
EMA & Mc5 & $1: 400$ & BioGenex, San Ramon, USA \\
Pancytokeratin & MNF116 & $1: 500$ & DAKO \\
S-100 protein & Polyclonal & $1: 2000$ & DAKO \\
GFAP & GA-5 & $1: 200$ & DCS, Hamburg \\
Calponin & CALP & $1: 400$ & DAKO, Glostrup, Denmark \\
\hline
\end{tabular}

histochemically by the labeled streptavidin biotin technique using commercially available antibodies listed in Table 1. Appropriate positive and negative controls were used throughout.

\section{Fluorescent In Situ Hybridization Analysis}

For the detection of a translocation involving the EWSR1 gene on 22q12 and the FUS gene on 16p11 a directly FITC/Rhodamine-labeled break apart probe (Abbott, Bergisch Gladbach, Germany) was used.

Fluorescent in situ hybridization analysis (FISH) was performed on $3 \mu \mathrm{M}$ sections of formalin-fixed, paraffin-embedded tissue after baking at $65{ }^{\circ} \mathrm{C}$ for $16 \mathrm{~h}$, deparaffinization with xylene and dehydration with ethanol. All tissue sections were pretreated with a $30 \%$ solution of Oncor pretreatment powder in $2 \times$ SSC and digested for $10 \mathrm{~min}$ with Proteinase $\mathrm{K}$ following the instructions of the suppliers (Q-Biogene, Heidelberg, Germany). After a second dehydration step, the probes were applied to the sections, and the covered slides were sealed with rubber cement, heat-denatured and hybridized at $37^{\circ} \mathrm{C}$ for $16 \mathrm{~h}$. All sections were counterstained with DAPI II in mounting medium $(125 \mathrm{ng} / \mathrm{ml}$, Abbott $)$ and visualized under a Zeiss Axioplan microscope using a HBO100 lamp and the appropriate filters for the three fluorescent dyes. A negative control has been used in each case. A case was considered having a break in case 10 of 50 counted tumor cells showed separation of a red and green signal.

\section{Results}

Eighteen cases were studied. Clinical data are shown in Table 2. Briefly, there were 7 females and 11 males with an age range of 34-86 years (mean, 58 years; median, 56 years).

Table 2 Clinical data and histological diagnosis

\begin{tabular}{|c|c|c|c|c|c|c|c|}
\hline Case & $\begin{array}{l}\text { Sex/age } \\
\text { (in } M / F / \text { years) }\end{array}$ & Location & $S C$ & $\begin{array}{l}\text { Size } \\
(\mathrm{cm})\end{array}$ & Diagnosis & $R S$ & $\begin{array}{l}\text { Follow-up } \\
\text { (months) }\end{array}$ \\
\hline 1 & $\mathrm{M} / 34$ & Occipital & - & 1.0 & Mixed tumor & RM & NA \\
\hline 2 & $\mathrm{M} / 86$ & Scrotum & - & 1.2 & Mixed tumor & RM & NA \\
\hline 3 & $\mathrm{M} / 48$ & Face & - & 0.5 & Mixed tumor & R0 & NA \\
\hline 4 & $\mathrm{M} / 55$ & Nose & - & 0.3 & Mixed tumor & $\mathrm{RM}$ & NA \\
\hline 5 & $\mathrm{M} / 72$ & Frontoparietal & - & 1.2 & Mixed tumor & RM & NED, 51 \\
\hline 6 & $\mathrm{M} / 57$ & Temple & - & 0.5 & Mixed tumor & R0 & NED, 12 \\
\hline 7 & $\mathrm{~F} / 61$ & Parietal & - & 1.7 & Mixed tumor & R1 & NA \\
\hline 8 & $\mathrm{~F} / 54$ & Face & - & 0.4 & Mixed tumor & Ro & NA \\
\hline 9 & $\mathrm{M} / 68$ & Face & - & 0.8 & Mixed tumor & R0 & NA \\
\hline 10 & $\mathrm{~F} / 51$ & Back & + & 1.5 & Myoepithelioma, rec & RM & NA \\
\hline 11 & $\mathrm{M} / 55$ & Distal lower leg & + & 1.2 & Myoepithelioma & R0 & NED, 6 \\
\hline 12 & $\mathrm{M} / 50$ & Ear & - & 1.5 & Myoepithelioma & $\mathrm{R} 1$ & NA \\
\hline 13 & $\mathrm{~F} / 65$ & Arm & - & 1.5 & Myoepithelioma & R0 & NED, 17 \\
\hline 14 & $\mathrm{M} / 66$ & Thumb & + & 1.5 & Myoepithelioma & RM & NA \\
\hline 15 & $\mathrm{~F} / 49$ & Finger & - & 0.5 & Myoepithelioma & Ro & NA \\
\hline 16 & $\mathrm{~F} / 45$ & Thigh & + & 0.7 & Myoepithelioma & Ro & NA \\
\hline 17 & $\mathrm{M} / 57$ & Plantar & NA & NA & Myoepithelioma & R1 & NA \\
\hline 18 & $\mathrm{~F} / 70$ & Cheek & + & 0.8 & Myoepithelial ca & Ro & NED, 72 \\
\hline
\end{tabular}

Abbreviations: ca, carcinoma; NA, not available; NED, no evidence of disease; R0, complete resection; R1, microscopically positive resection margins; rec, recurrence; RM, marginal resection; RS, resection status; SC, subcutaneous. 
Mixed tumors $(n=9)$ occurred mostly on the head $(n=8)$, whereas one was localized at the scrotum. Most of the myoepitheliomas $(n=6)$ occurred at the extremities; one case each arose on the back and head. There was one myoepithelial carcinoma occurring at the cheek. The tumor size ranged from 0.3 to $1.7 \mathrm{~cm}$ (mean $1.0 \mathrm{~cm}$ ). Mixed tumors were smaller than myoepitheliomas $(0.9 \mathrm{~cm}$ vs $1.2 \mathrm{~cm})$. All mixed tumors and three myoepitheliomas were limited to the dermis; four myoepitheliomas showed involvement of the subcutis. In one myoepithelioma, the depth was not known. The myoepithelial carcinoma infiltrated the subcutis (Table 2).

Histologically, all mixed tumors were well circumscribed; seven had a nodular and two a nodular cystic architecture (Figure 1). Ductal structures were present by definition in all cases (Figure 2), sometimes cystic dilated and sometimes with apocrine features $(n=3)$. Cribriform structures were present in one case. The myoepithelial component was arranged around ducts and also in nests, cords and strands, solid and reticular. Although epithelioid myoepithelial cells occurred in all cases, spindle cells were present in three cases and plasmocytoid

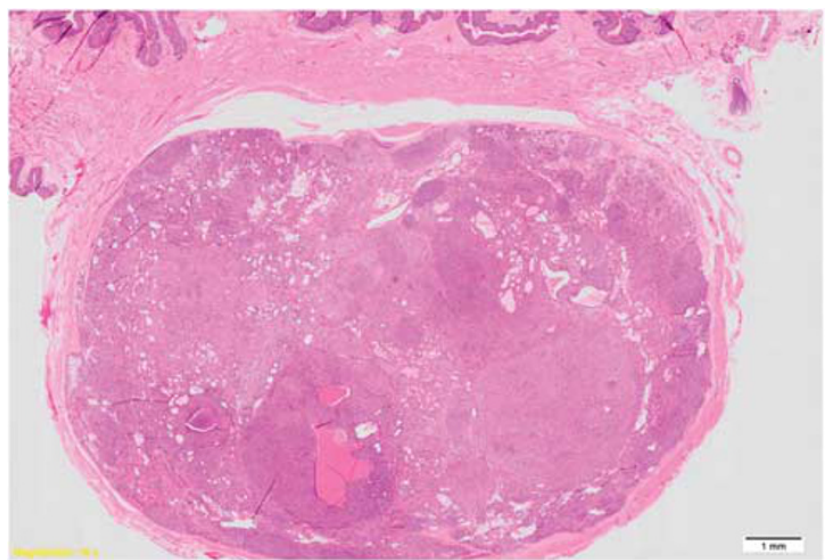

Figure 1 All mixed tumors had a nodular architecture (Case 2).

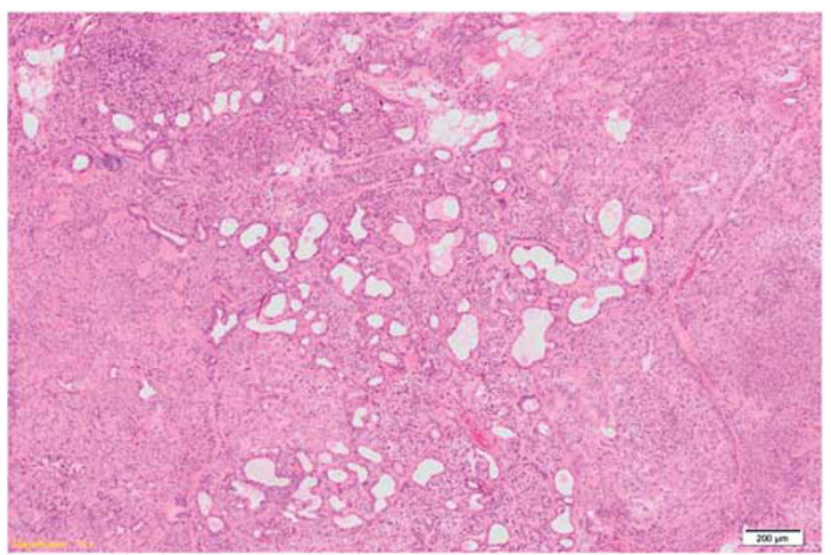

Figure 2 Glandular structures and a varying number of myoepithelial cells were present in all mixed tumors (Case 2). cells in five cases. One case showed focally clear cells. Metaplastic fat cells were a feature in Cases 1, 2 and 7 , and squamous metaplasia in Cases 1 and 6. Ischemic central necrosis was seen in Case 5 . No case showed mitotic figures, and in Case 3 focal moderate atypia was noted. The stroma was myxoid at least focally in all cases, chondroid in four cases, hyaline and/or collagenous in five and three cases, respectively.

Three of the myoepitheliomas displayed a multinodular and three a nodular pattern, one of them with an epidermal collarette (Figure 3). A nodularcystic appearance was noted in one case. One neoplasm was not sharply demarcated.

In each myepithelioma, different cell types were present. Two tumors contained mainly spindle cells and some epitheloid cells, mostly arranged in bundles (Figure 4). Two tumors with a nested pattern had a predominantly plasmocytoid/epithelioid composition. In one of them, double nuclei were present as seen in plasma cells. Epithelioid and spindle cells were observed in four cases accompanied by clear cells in Case 10 and plasmocytoid cells in Case 12. Strands, cords and nests

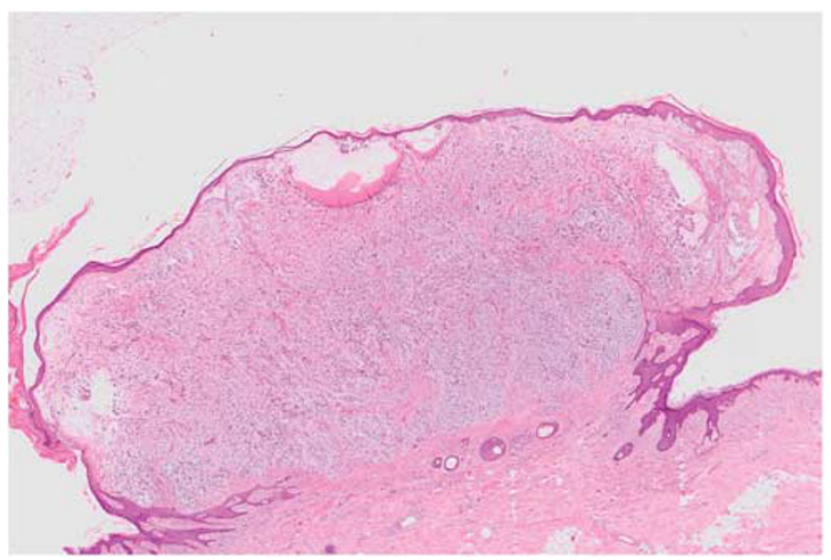

Figure 3 Case 13 was an exophytic lesion with an epidermal collarette.

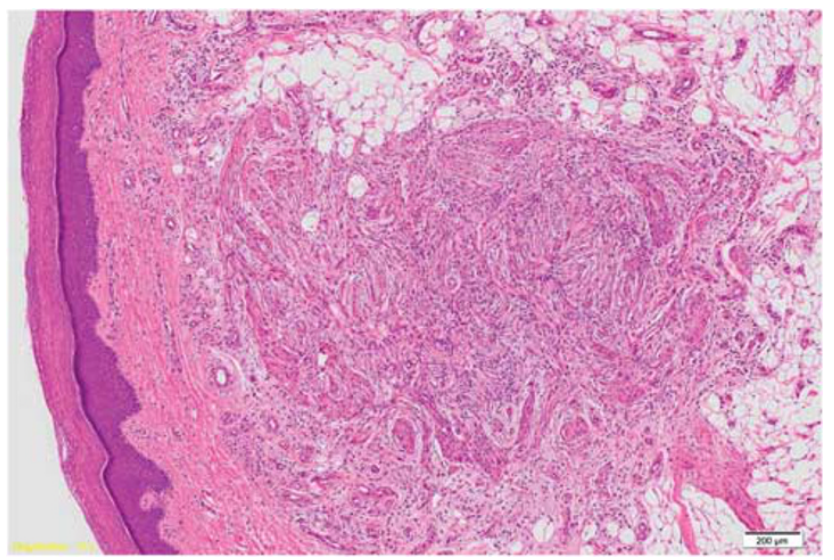

Figure 4 Case 11 showed predominantly spindle-shaped myoepithelial cells and also metaplastic adipocytes. 
were found in the latter cases (Figure 5). The matrix was at least focally myxoid in five cases, collagenous/hyaline in five cases and focally chondroid in one case. Adipocytic differentiation occurred in one case. Little atypia was present in Case 11 and moderate atypia in Case 13 (Figure 6). The last one and Case 14 had 1 mitotic figure per $10 \mathrm{HPF}$, whereas in all other cases, mitoses were absent.

The myoepithelial carcinoma (Case 18) was described earlier by the authors (Mentzel et $a l^{3}$ ) and represented an infiltrating neoplasm composed of atypical spindle cells with enlarged and pleomorphic nuclei containing prominent nucleoli. There were 5 mitoses per $10 \mathrm{HPF}$. Focal tumor necrosis was present (Figure 7).

Immunohistochemical results are shown in Table 3. All cases tested were positive for EMA and calponin, whereas S100, CK, ASMA and GFAP were expressed in $90 \%, 80 \%, 78 \%$ and $50 \%$ of the cases tested, respectively (Figures 8 and 9).

By FISH analysis, 7 out of 16 cases (44\%) exhibited EWSR1 rearrangement. Four of them were mixed tumors, two were myoepitheliomas and one

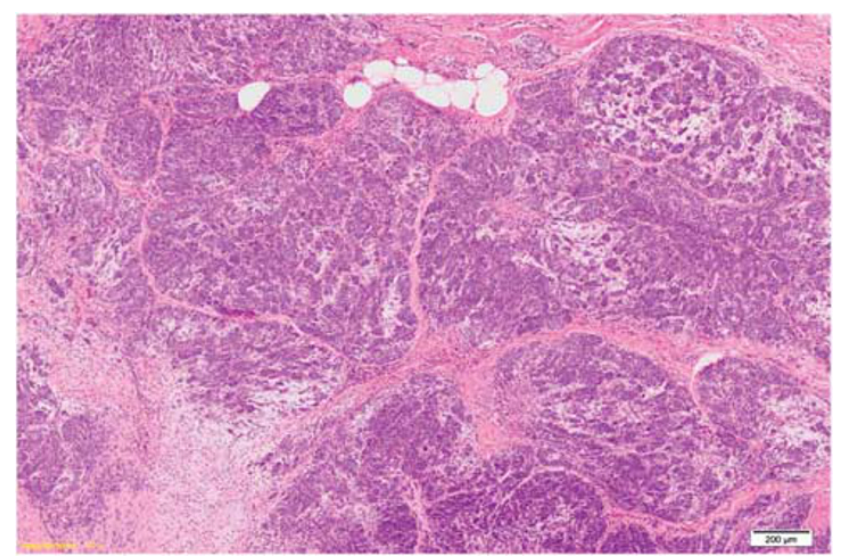

Figure 5 Case 10 was mainly composed of epithelioid cells with a predominantly nested growth pattern. Note the chondromyxoid stroma.

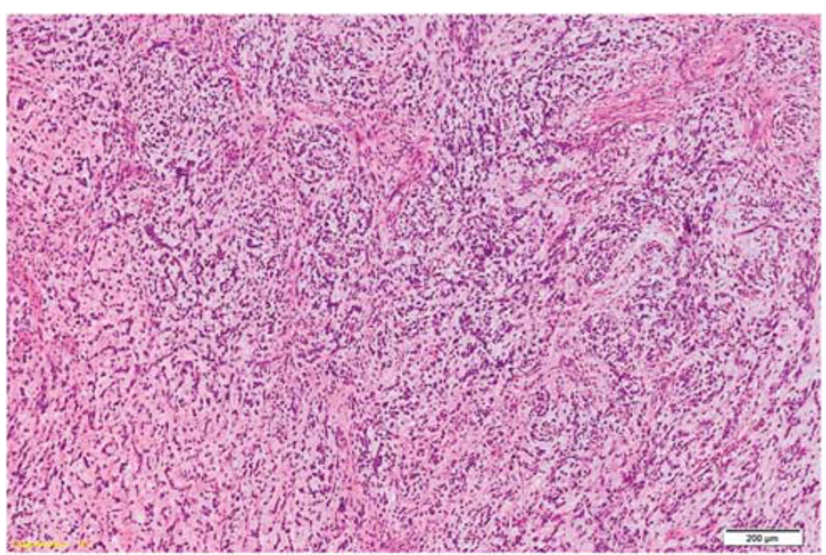

Figure 6 Moderate atypia was seen in Case 13. Note the reticular architecture and the myxoid matrix.

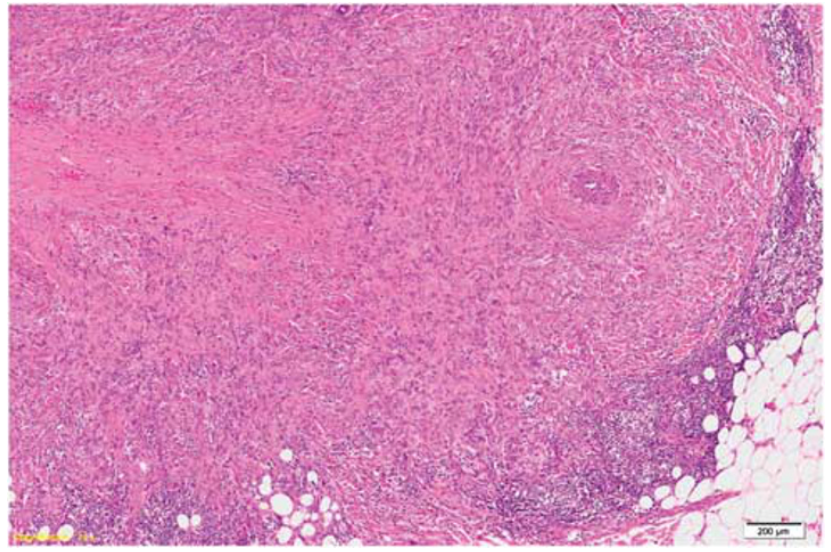

Figure 7 Myoepithelial carcinoma consisted of atypical spindleshaped cells with infiltrative growth (Case 18).

Table 3 Immunohistochemical results

\begin{tabular}{ccccccc}
\hline Case & CK & EMA & ASMA & Calponin & S100 & GFAP \\
\hline 3 & + & ND & ND & ND & + & ND \\
9 & ND & ND & f+ & ND & + & ND \\
10 & + & ND & f+ & f+ & + & + \\
11 & f+ & + & + & + & f+ & ND \\
12 & + & ND & + & ND & ND & - \\
13 & - & + & - & ND & + & ND \\
14 & + & f+ & ND & f+ & + & ND \\
15 & + & ND & f+ & ND & f+ & ND \\
16 & - & + & + & ND & f+ & ND \\
17 & + & ND & - & ND & + & ND \\
18 & + & + & + & ND & - & ND \\
& & & & & & \\
\hline \multirow{2}{*}{ Total +} & & & & & & \\
& $8 / 10$ & $5 / 5$ & $7 / 9$ & $3 / 3$ & $9 / 10$ & $1 / 2$ \\
& $80 \%$ & $100 \%$ & $78 \%$ & $100 \%$ & $90 \%$ & $50 \%$ \\
\hline
\end{tabular}

Abbreviations: f, focally; ND, not done.

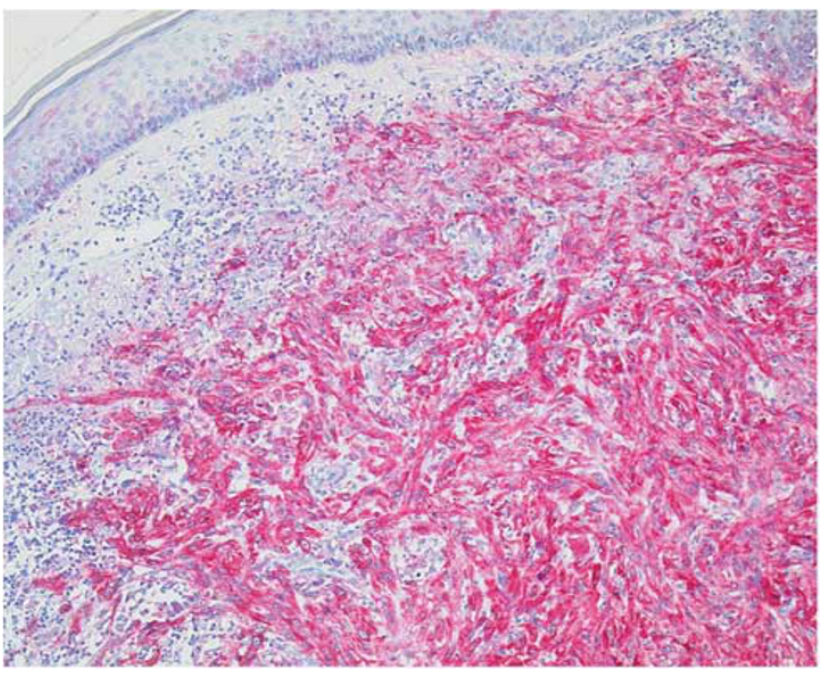

Figure 8 Atypical spindle cells expressed EMA in Case 18. 


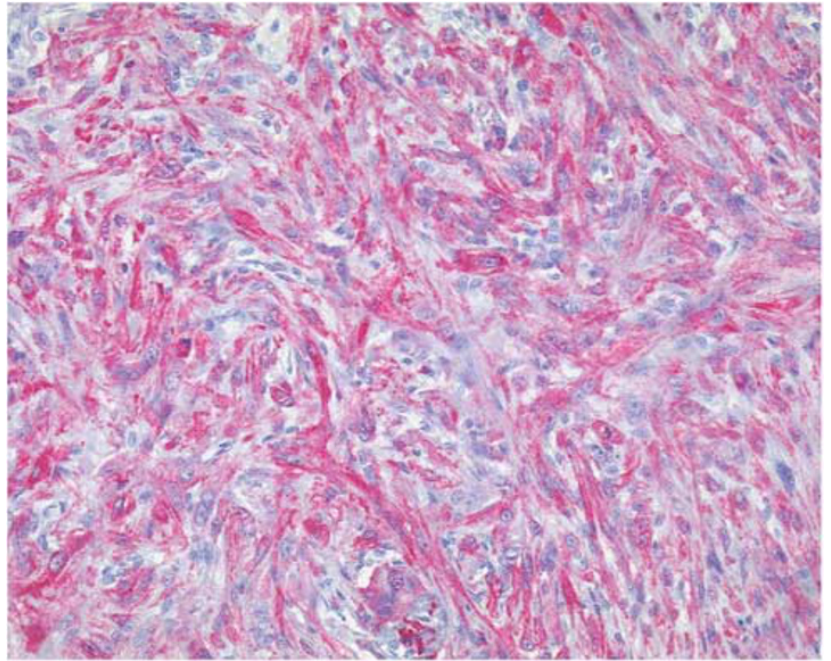

Figure 9 Expression of ASMA in the myoepithelial carcinoma.

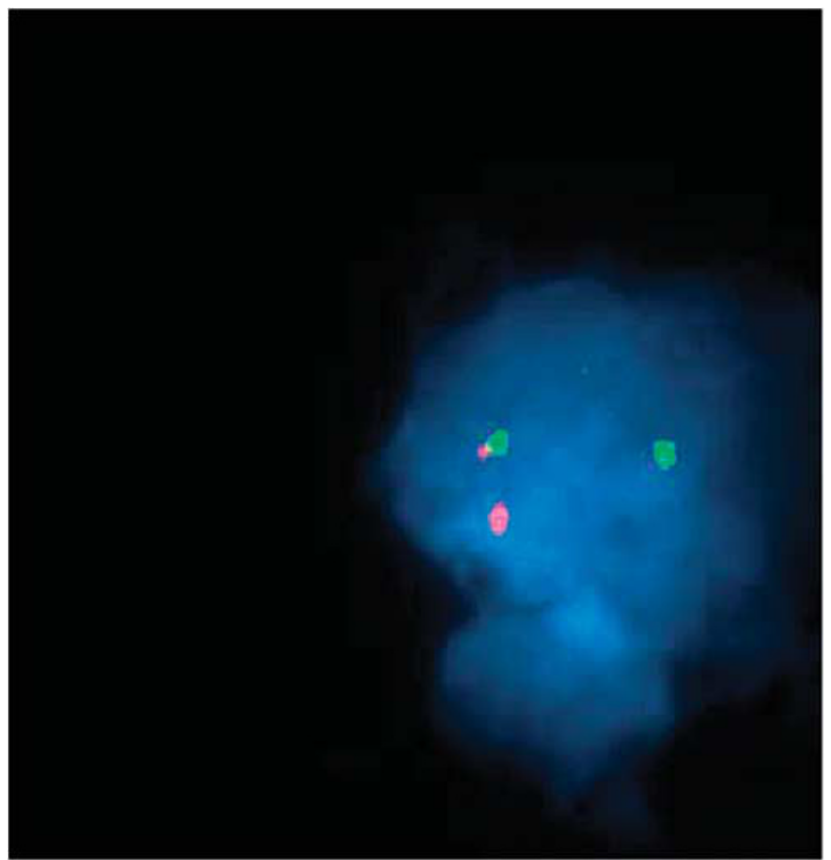

Figure 10 Fluorescent in situ hybridization analysis (FISH) of a myoepithelioma (Case 15) with a break-apart signal for EWSR1.

was the myoepithelial carcinoma (Figure 10). Separation of the signal was generally seen in at least $20 \%$ of the nuclei. There were no morphological differences between positive and negative cases.

FUS gene rearrangement examined in the EWSR1 negative instances was not detected in any of them $(n=9)$ (Table 4).

In nine cases, the tumors were excised with wide tumor-free margins, and in six cases, the tumor was marginally excised. Microscopically tumor-positive margins were observed in three cases (Table 2).

Follow-up data were available in five patients (two with myoepitheliomas, two with mixed
Table 4 FISH results for EWSR1 and FUS rearrangement

\begin{tabular}{|c|c|c|c|}
\hline Case & EWSR1 & & FUS \\
\hline 1 & + & $(17 / 50)$ & ND \\
\hline 2 & + & $(19 / 50)$ & ND \\
\hline 3 & + & $(11 / 50)$ & ND \\
\hline 4 & + & $(12 / 50)$ & ND \\
\hline 5 & - & & - \\
\hline 6 & $\mathrm{x}$ & & - \\
\hline 7 & - & & - \\
\hline 8 & - & & - \\
\hline 9 & - & & - \\
\hline 10 & + & $(14 / 50)$ & ND \\
\hline 11 & - & (8/50) & ND \\
\hline 12 & - & & - \\
\hline 13 & - & & - \\
\hline 14 & - & & - \\
\hline 15 & + & $(12 / 38)$ & ND \\
\hline 16 & $\mathrm{x}$ & & $\mathrm{x}$ \\
\hline 17 & - & & - \\
\hline 18 & + & $(10 / 50)$ & ND \\
\hline
\end{tabular}

Abbreviations: +, break apart signal/rearrangement (in out of nuclei counted); -, no break apart signal/rearrangement; x, analysis failed; ND, not done.

tumors, one with a myoepithelial carcinoma) without evidence of disease during a follow-up time with a range of 6-72 months (mean, 32 months) (Table 2).

\section{Discussion}

Cutaneous myoepithelial tumors are divided into mixed tumors and myoepitheliomas depending on the occurrence of ductal structures defining the former. ${ }^{2,3}$ They also include myoepithelial carcinomas, which are defined by atypical cytological features. ${ }^{3,4}$ In the absence of atypia, high mitotic index, local invasion and tumor necrosis should raise concern. ${ }^{4,8}$

Earlier studies suggested that cutaneous myoepitheliomas and their soft tissue counterparts represent points along a clinicopathological spectrum that was apparently extended to include myoepithelial tumors of the bone and of some visceral sites (lung). ${ }^{1,2,5,10}$ Although this entity, in the above described localizations, is well established by now, the protean morphological and immunohistochemical range is still hampering the histopathological diagnosis, and the true frequency of these neoplasms is unclear until today.

This study also mirrors the morphological and immunohistochemical heterogeneity by the presence of a variable (immuno)phenotype in all cases. A (chondro)myxoid/hyaline matrix was almost always existent, and adipocytes as a heterologous element were seen in four of our cases. All these observations are well-reported earlier. ${ }^{1-4,6}$

The occurrence of EWSR1 rearrangement in mixed tumors, myoepitheliomas and rare myoepithelial carcinomas emphasizes that these lesions belong to a spectrum of cutaneous myoepithelial neoplasms. 
Furthermore, EWSR1 rearrangement found in $44 \%$ of cutaneous myoepithelial tumors in our series, provide a genetic link with their counterparts in soft tissue, bone and the lung. Most of the reported EWSR1 rearrangements occur in soft tissue myoepithelial tumors, which means that $45 \%$ of them show this abnormality. ${ }^{10}$ This is in concert with our results in cutaneous tumors. POUF5F1 is one of the described fusion genes in the soft tissue tumors and is associated with clear cell morphology and younger age. ${ }^{10}$ Other known fusion partners are $P B X 1$ and $Z N F 444 .^{10-12}$ In $42 \%$ of the described EWSR1 rearranged cases, these fusion partners have been identified so far. For $P B X 1$ and POU5F1, the same frequency was detected and a EWS1-ZNF444 fusion was seen in only one case of the lung. ${ }^{10}$

When we consider the low incidence of FUS rearrangement in the series by Antonescu et $a 1^{10}$ with one positive pulmonal myoepithelial tumor of total 66 cases, it is not surprising that we did not find a FUS gene rearrangement in our cases. ${ }^{10}$

Hidradenoma, a biphasic epithelial skin appendage tumor with occurrence of ductal/glandular and cystic structures, earlier thought to be a clear cell myoepithelioma, ${ }^{13,14}$ possess in a subset of cases the specific fusion CRTC1-MAML2, which has been also described in mucoepidermoid carcinomas and Warthin's tumors of salivary glands. ${ }^{15,16}$ One study demonstrated the occurrence of EWSR1-POUF5F1 fusion in hidradenomas, ${ }^{17}$ whereas Antonescu et $a l^{10}$ did not find an EWSR1 rearrangement in five eccrine hidradenomas. ${ }^{10}$ Therefore, one could speculate whether these described lesions by Möller et $a l^{17}$ are more related to myoepithelial tumors. ${ }^{17}$

The much more common occurring and investigated myoepithelial tumors of the salivary glands are known for a different genetic background, which contains rearrangements of PLAG1 and HMGA2. ${ }^{18}$

A differential diagnosis of cutaneous myoepithelial tumors in our opinion represents epithelioid sarcoma, especially the very rarely occurring myxoid variant. Their occurrence is mostly as in myoepitheliomas at the distal extremities. This myxoid variant always shows at least focally classical features of epithelioid sarcoma. ${ }^{19}$ Although there is an immunohistochemical overlap with positivity for keratin and EMA, INI1 protein, absent in the majority of cases of epitheloid sarcoma, is a reliable marker for supporting the diagnosis. ${ }^{20-22}$ In contrast, cutaneous myoepithelial tumors have a retained INI1 protein in all of our cases (data not shown). In this context, it should be noted that in a subset of myoepithelial carcinomas of soft tissue the INI1 protein is absent. ${ }^{9}$ Another helpful discriminating marker is CD34, which is at least in $50 \%$ of epithelioid sarcomas positive. ${ }^{20,23,24}$ Although genetic aberrations in INI1, located on 22q11, are reported in epithelioid sarcoma, EWSR1 rearrangements are never described. ${ }^{19,22,25,26}$
On histomorphological grounds, extraskeletal myxoid chondrosarcomas and ossifying fibromyxoid tumors may also enter the differential diagnosis. Although extraskeletal myxoid chondrosarcomas are classically located in the deep soft tissues, ossifying fibromyxoid tumors are commonest located in the subcutis, and involvement of the skin has rarely been reported. These tumors show a distinctive lobulation and in most cases a bone shell is evident. ${ }^{27-29}$ Metaplastic bone formation known in soft tissue myoepithelial tumors is not described in skin lesions. ${ }^{1-8}$ Moreover, the intratumoral cytological and architectural heterogeneity of myoepithelial tumors is not a feature of ossifying fibromyxoid tumors in which uniform round to oval cells in cords and nests set in a myxohyaline stroma. ${ }^{4,6,7}$ Immunohistochemical stains in this setting are of limited value because of the overlap with positivity for S100, GFAP, myogenic markers and rarely also keratins. ${ }^{4,6,7,27-29}$ Even though in a small number of cases investigated, ossifying fibromyxoid tumors show no abnormality in EWSR 1 . $^{10}$

In summary, our study demonstrated that cutaneous myoepithelial tumors harbor EWSR1 rearrangement in a subset of cases, and therefore are genetically related to soft tissue and bone myoepithelial tumors and the visceral counterpart in the lung. Regarding the fusion genes of EWSR1 in cutaneous tumors, further investigations are mandatory.

In addition, the relative low incidence of EWSR1 rearrangement in myoepithelial tumors comparing with other tumors harboring translocations, alternative genetic mechanisms, more specifically, rearrangements of other genes are yet to be discovered. Apparently FUS here has a tangential role. ${ }^{10}$

\section{Disclosure/conflict of interest}

The authors declare no conflict of interest.

\section{References}

1 Michal M, Miettinen M. Myoepitheliomas of the skin and soft tissues. Report of 12 cases. Virchows Arch 1999;434:393-400.

2 Kutzner H, Mentzel T, Kaddu S, et al. Cutaneous myoepithelioma: an under-recognized cutaneous neoplasm composed of myoepithelial cells. Am J Surg Pathol 2001;25:348-355.

3 Mentzel T, Requena L, Kaddu S, et al. Cutaneous myoepithelial neoplasms: clinicopathologic and immunohistochemical study of 20 cases suggesting a continuous spectrum ranging from benign mixed tumor of the skin to cutaneous myoepithelioma and myoepithelial carcinoma. J Cutan Pathol 2003;30: 294-302.

4 Hornick JL, Fletcher CDM. Cutaneous myoepithelioma: a clinicopathologic and immunohistochemical study of 14 cases. Hum Pathol 2004;35:14-24. 
5 Kilpatrick SE, Hitchcock MG, Kraus MD, et al. Mixed tumors and myoepitheliomas of soft tissue: a clinicopathologic study of 19 cases with a unifying concept. Am J Surg Pathol 1997;21:13-22.

6 Gleason BC, Hornick JL. Myoepithelial tumours of skin and soft tissue: an update. Diagn Histopathol 2008;14:552-562.

7 Hornick JL, Fletcher CDM. Myoepithelial tumors of soft tissue. A clinicopathologic and immunohistochemical study of 101 cases with evaluation of prognostic parameters. Am J Surg Pathol 2003;27:1183-1196.

8 Bates AW, Baithun SI. Atypical mixed tumor of the skin: histologic, immunohistochemical, and ultrastructural features in three cases and a review of the criteria for malignancy. Am J Dermatopathol 1998;20:35-40.

9 Gleason BC, Fletcher CDM. Myoepithelial carcinoma of soft tissue in children: an aggressive neoplasm analysed in a series of 29 cases. Am J Surg Pathol 2007;31:1813-1824.

10 Antonescu CR, Zhang L, Chang NE, et al. EWSR1POU5F1 fusion in soft tissue myoepithelial tumors. A molecular analysis of sixty-six cases, including soft tissue, bone and visceral lesions showing common involvement of EWSR1 gene rearrangement. Genes Chromosomes Cancer 2010;49:1114-1124.

11 Brandal P, Panagopoulos I, Bjerkehagen B, et al. Detection of a $\mathrm{t}(1 ; 22)(\mathrm{q} 23 ; \mathrm{q} 12)$ translocation leading to an EWSR1-PBX1 fusion gene in a myoepithelioma. Genes Chromosomes Cancer 2008;47:558-564.

12 Brandal P, Panagopoulos I, Bjerkehagen B, et al. $\mathrm{t}(19 ; 22)(\mathrm{q} 13 ; \mathrm{q} 12)$ Translocation leading to the novel fusion gene EWSR1-ZNF444 in soft tissue myoepithelial carcinoma. Genes Chromosomes Cancer 2009;48: 1051-1056.

13 Lever WF. Myoepithelial sweat gland tumor, myoepithelioma; report of three cases with a review of the literature. Arch Derm Syphilol 1948;57:332-347.

14 Requena L, Kiryu H, Ackerman AB. Apocrine Hidradenoma. Neoplasms with Apocrine Differentiation. Lippincott-Raven: Philadelphia, PA, 1998, pp 243.

15 Winnes M, Molne L, Suurkula M, et al. Frequent fusion of the CRTC1 and MAML2 genes in clear cell variants of cutaneous hidradenomas. Genes Chromosomes Cancer 2007;46:559-563.

16 O'Neill ID. t(11;19) translocation and CRTC1-MAML2 fusion oncogene in mucoepidermoid carcinoma. Oral Oncol 2009;45:2-9.

17 Möller E, Stenman G, Mandahl N, et al. POU5F1, encoding a key regulator of stem cell pluripotency, is fused to EWSR1 in hidradenoma of the skin and mucoepidermoid carcinoma of the salivary glands. J Pathol 2008;215:78-86.

18 Stenman G. Fusion oncogenes and tumor type specificity-insights from salivary gland tumors. Semin Cancer Biol 2005;15:224-235.

19 Flucke U, Hulsebos TJM, van Krieken JHJM, et al. Myxoid epithelioid sarcoma: a diagnostic challenge. A report on six cases. Histopathology 2010;57:753-759.

20 Chbani L, Guillou L, Terrier P, et al. Epithelioid sarcoma. A clinicopathologic and immunohistochemical analysis of 106 cases from the French Sarcoma Group. Am J Clin Pathol 2009;13:222-227.

21 Hornick JL, Dal Cin P, Fletcher CDM. Loss of INI1 expression is characteristic of both conventional and proximal-type epithelioid sarcoma. Am J Surg Pathol 2009;33:542-550.

22 Kohashi K, Izumi T, Oda $\mathrm{Y}$, et al. Infrequent SMARCB1/INI1 gene alteration in epithelioid sarcoma: a useful tool in distinguishing epithelioid sarcoma from malignant rhabdoid tumor. Hum Pathol 2009;40:349-355.

23 Guillou L, Wadden C, Coindre JM, et al. Proximal-type epithelioid sarcoma, a distinctive aggressive neoplasm showing rhabdoid features: clinicopathologic, immunohistochemical, and ultrastructural study of a series. Am J Surg Pathol 1997;21:130-146.

24 Miettinen M, Fanburg-Smith JC, Virolainen M, et al. Epithelioid sarcoma: an immunohistochemical analysis of 112 classical and variant cases and a discussion of the differential diagnosis. Hum Pathol 1999;30: 934-942.

25 Modena P, Lualdi E, Facchinetti F, et al. SMARCB1/ INI1 tumor suppressor gene is frequently inactivated in epithelioid sarcoma. Cancer Res 2005;65: 4012-4019.

26 Gasparini P, Facchinetti F, Boeri M, et al. Prognostic determinants in epithelioid sarcoma. Eur J Cancer 2011;47:287-295.

27 Fletcher CDM, Unni K, Mertens F, (eds). World Health Organization Classification of Tumours. Pathology and Genetics of Tumors of Soft tissue and Bone. IARC Press: Lyon, France, 2002, pp 196, 213.

28 Folpe AL, Weiss SW. Ossifying fibromyxoid tumor of soft parts. A clinicopathologic study of 70 cases with emphasison atypical and malignant variants. Am J Surg Pathol 2003;27:421-431.

29 Miettinen M, Finnell V, Fetsch JF. Ossifying fibromyxoid tumor of soft parts-A clinicopathologic and immunohistochemical study of 104 cases with longterm follow-up and a critical review of the literature. Am J Surg Pathol 2008;32:996-1005. 